\title{
Animal instinct helps doctors ferret out disease
}

In 2007, David Dosa, a geriatrician at Brown University in Providence, Rhode Island, reported the curious case of a white-bellied cat that purportedly could predict death among the elderly residents of a local Rhode Island nursing home. Researchers hypothesized that Oscar-the "furry grim reaper" or "four-legged angel of death," as the media called him-could smell ketones, the chemicals released by dying cells, and this drew the feline forecaster toward people in their final days. "I think all animals are able to do things like this," says Dosa, who wrote a book about Oscar that was published last year.

But it's not just death that animals can sniff out. A growing number of scientists are now turning to Mother Nature to help with the early detection of a number of ailments, including cancer and tuberculosis. Below are four of the most skilled disease hunters from the animal kingdom.

\section{Going to the dogs}

At the Pine Street Foundation in Marin County, California, researchers are teaching old dogs new tricks-specifically, how to detect human cancer before people even know that they have the disease. With noses thought to pick up chemicals at concentrations as low as a few

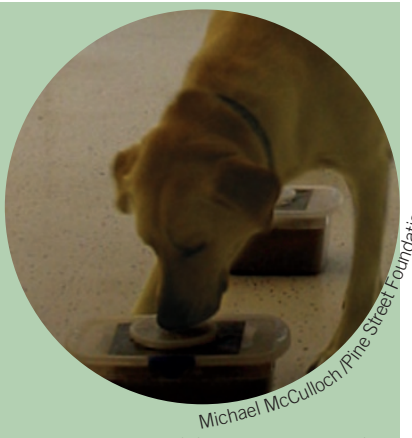
parts per trillion, these determined canine constables are trained to recognize the telltale signs of tumors lingering in exhaled human breath. Results published in 2006 indicate that the dogs (Canis lupus familiaris) can identify both breast and lung cancers at their earliest stages with at least $88 \%$ accuracy (Integr. Cancer Ther. 5, 30-39, 2006). Similarly, French researchers reported this month that a Belgian shepherd dog could recognize the odor of prostate cancer in human urine with a $91 \%$ success rate (Eur. Urol. 59, 197-201, 2011). The Pine Street pack, which includes two Labrador retrievers and three Portuguese water dogs, are now on the hunt for ovarian cancer, according to the foundation's team leader Michael McCulloch.

\section{I smell a rat}

Rats are often vectors of nasty disease. But in the case of the African giant pouched rat (Cricetomys gambianus) - a footlong rodent so named because of its large, food-storing cheek pouches-these vermin might actually help prevent the spread of illness. First enlisted in 2003 by the Tanzania-based nonprofit

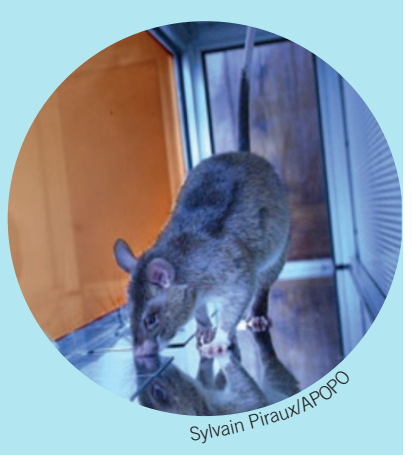
organization APOPO to uncover landmines in Mozambique, the giant rats can also rapidly sense the smell of the tuberculosis bacterium in human saliva. Reporting in December, APOPO researchers, in collaboration with behavioral psychologist $\mathrm{Al}$ Poling of Western Michigan University in Kalamazoo, found that trained rats correctly identified laboratory-confirmed cases of tuberculosis in human sputum samples with greater than $90 \%$ precision. What's more, the rats-called HeroRATS-also sensed close to $50 \%$ more tuberculosis-positive samples than those flagged by conventional microscope tests alone (Am. J. Trop. Med. Hyg. 83, 1308-1310, 2010). "If we increase case detection... we are saving a lot of lives," Poling says.

\section{To bee or not TB}

Trained honey bees are on the hunt for much more than pollenproducing flowers at Inscentinel, a biotech company based at the UK Biotechnology and Biological Sciences Research Council's Rothamsted Research center, located 50 kilometers north of London. Naturally armed with antennae jam-packed with chemical

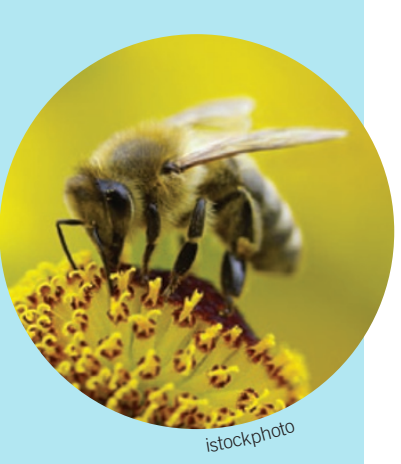
sensors, the company's swarm of honey bees (Apis mellifera) can differentiate between bovine tuberculosis-causing microbes and other closely related bacteria through smell alone. "What we are trying to do is develop a cheap technology to screen a lot of people for tuberculosis in Africa," explains Inscentinel bee specialist Mathilde Briens. Housed in thumb-size cartridges within a machine that resembles a handheld vacuum cleaner, the bees have been conditioned to stick out their tongues when they detect the desired scent, which trips an optical sensor detected by the machine. After a hard two hours' work, the bees return to their hives.

\section{Mouse hunt}

Common house mice (Mus musculus) also receive mighty high marks in early cancer detection. In a study published last year, researchers showed that wild-type inbred mice could correctly detect lung cancer after sniffing the urine of fellow mice nine times out of ten (PLoS One 5, e8819, 2010). In hopes of designing a mechanical test based on chemical signatures alone, the

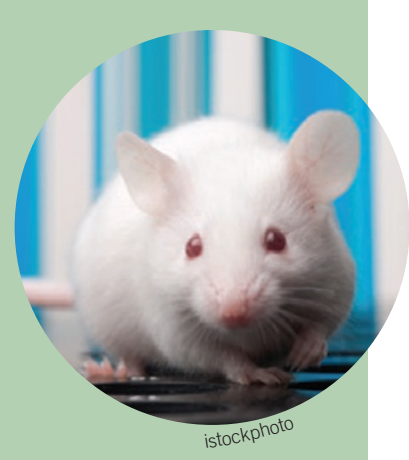
study authors, led by olfactory expert Gary Beauchamp of the Monell Chemical Senses Center in Philadelphia, are now using gas chromatography coupled to mass spectrometry techniques to zero in on the fingerprint of volatile biomarkers in mouse pee. "Nobody is going to truly accept animals as a diagnostic tool," says Beauchamp. "You need an instrument." Collaborator Bruce Kimball of the US Department of Agriculture's National Wildlife Research Center in Fort Collins, Colorado is also training these mice to track avian influenza. 